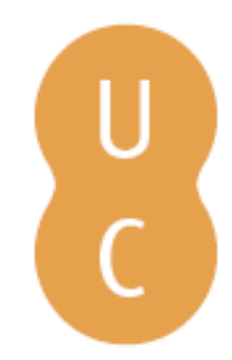

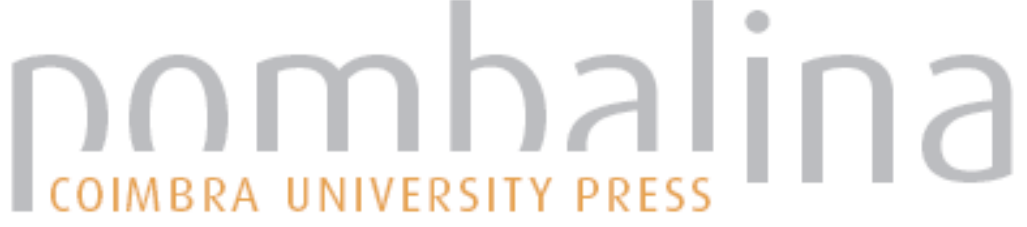

\section{Despersonalização da Ciência: técnicas de encantamento da Ciência}

\author{
Autor(es): $\quad$ Carrilho, Nuno \\ Publicado por: Imprensa da Universidade de Coimbra \\ URL \\ persistente: URI:http://hdl.handle.net/10316.2/36631 \\ DOI: $\quad$ DOI:http://dx.doi.org/10.14195/978-989-26-0968-3_2
}

Accessed : $\quad$ 26-Apr-2023 15:22:14

A navegação consulta e descarregamento dos títulos inseridos nas Bibliotecas Digitais UC Digitalis, UC Pombalina e UC Impactum, pressupõem a aceitação plena e sem reservas dos Termos e Condições de Uso destas Bibliotecas Digitais, disponíveis em https://digitalis.uc.pt/pt-pt/termos.

Conforme exposto nos referidos Termos e Condições de Uso, o descarregamento de títulos de acesso restrito requer uma licença válida de autorização devendo o utilizador aceder ao(s) documento(s) a partir de um endereço de IP da instituição detentora da supramencionada licença.

Ao utilizador é apenas permitido o descarregamento para uso pessoal, pelo que o emprego do(s) título(s) descarregado(s) para outro fim, designadamente comercial, carece de autorização do respetivo autor ou editor da obra.

Na medida em que todas as obras da UC Digitalis se encontram protegidas pelo Código do Direito de Autor e Direitos Conexos e demais legislação aplicável, toda a cópia, parcial ou total, deste documento, nos casos em que é legalmente admitida, deverá conter ou fazer-se acompanhar por este aviso. 


\section{CADERNOS DE PSIOUIATRIA SOCIAL E CULTURAL}

\section{\# 0}

MANUEL JOÃO QUARTILHO (COORD.)

HELDER ALMEIDA

ISABEL FAZENDA

ISABEL GIL

LINDA FERNANDES

MARIA DE FÁTIMA SOUSA

NUNO CARRILHO

RITA ALCAIRE

IMPRENSA DA UNIVERSIDADE DE COIMBRA COIMBRA UNIVERSITY PRESS 


\section{Despersonalização da Ciência - Técnicas de Encantamento da Ciência}




\title{
Nuno Carrilho
}

Psiquiatra Assistente no CHBV - Centro Hospitalar do Baixo Vouga, Psicoterapeuta Interpessoal

\section{Resumo}

A observação participante é um método privilegiado para o estudo da complexidade das práticas científicas que apenas podem ser compreendidas no seu contexto cultural, pois permite o acompanhamento dos vários atuante sociais em acção, tal como a observação das práticas específicas. Este estudo acompanhou uma investigação realizada por um interno da especialidade de psiquiatria, permitindo o desvendar de múltiplos atuantes sociais, para além daqueles revelados pelo investigador no final do processo de investigação. Esses atuantes, como será demonstrado ao longo do trabalho, não devem ser negligenciados nos estudos sobre a ciência, visto terem a sua própria agencialidade sobre os processos de investigação.

Inferindo a partir de um contexto tão especifico como o internato da especialidade de Psiquiatria, que decorre no seio de um departamento psiquiátrico de um hospital distrital, podemos concluir que múltiplos atuantes sociais, uns visíveis e outros escamoteados, se associam e são associados ao longo do processo de investigação com o intuito de responder às diversas necessidades, tanto do investigador, como desses mesmos atuantes sociais.

Palavras chave: Psiquiatria Social e Cultural; Agencialidade e Atuantes Sociais; Estudo da Ciência; Epistemologia; Antropologia Médica;

\begin{abstract}
The participant observation is a privileged method to study the complexities of science in action, since they are culturally embedded, giving us the possibility to observe the various social agents, as to observe their specific practices.

This study follows the investigation made by a psychiatry intern, that aimed at unveiling several social agents, beside the ones revealed at the end of the scientific process. These social agents, as we shall reveal, should not be neglected in the science studies since they make their own agency upon the scientific process.

We can say, judging from what happens in a very specific context as is the psychiatric internship in a small psychiatric department, that several social agents, some visible and others hidden, are connected during the scientific process with the goal of answering several necessities, both from the investigators as from the social agents themselves.
\end{abstract}

Keywords: Social and Cultural Psychiatry; Agency and Social Agents; Science Studies; Epistemology; Medical Anthropology; 


\section{Introdução ${ }^{17}$}

Durante muito tempo a ciência e as suas práticas foram analisadas somente segundo os seus resultados e objetos produzidos, ignorando que os seus atores e objetos são atuantes sociais (Latour, 1987) pertencentes a um sistema cultural. Pretende-se neste texto mostrar e estudar o funcionamento da ciência como sistema cultural que tem as suas próprias regras, crenças, práticas e significados. Uma destas práticas está associada à capacidade de produzir conhecimento de forma neutra, que denominamos neste texto como Despersonalização da Ciência - derivado de um conceito psicopatológico -, e que como irá ser demonstrado, é fulcral para a diferenciação da ciência de outras práticas culturais. Assim sendo, citando Sarah Franklin (1995:165), a "Antropologia é uma ciência e tem as ferramentas necessárias para estudar a ciência como uma forma de cultura" e assim desvendar as práticas, regras, crenças e significados escamoteados no discurso da ciência oficial. Este estudo demonstra que o discurso oficial da ciência transforma processos complexos em processos simples (Law \& Mol, 2002) e que visam a persuasão (Latour, 1987, 1993, 1996) e o encantamento (Gell, 1988,1992) de determinadas comunidades. Para estudar estes processos complexos optou-se pelo método etnográfico, a exemplo de Bruno Latour (1987) e Annemarie Mol (2002a, 2002b), acompanhando o percurso de um médico, enquanto interno da especialidade de psiquiatria. Esta observação participante permitiu criar descrições densas das práticas necessárias para a execução de um processo de investigação, por parte de um interno da especialidade de psiquiatria, e assim desvendar os múltiplos atuantes sociais (visíveis ou escamoteados) que realizaram agencialidade sobre esse processo e sobre o interno da especialidade.

\section{Escolha(s) do estudo}

A intenção inicial deste estudo não era o estudo das práticas científicas, mas sim o estudo da comunidade médica hospitalar. Esta mudança no tema de estudo deveu-se muito à influência do orientador da Tese de Mestrado intitulada "Despersonalização Voluntária do Ser: Ontologias das Práticas Científicas", em que se baseia este texto, o Prof. Dr. Luís Quintais, com trabalho de campo e bibliográfico desenvolvido na área da psiquiatria (Quintais, 2000a, 2000b, 2001, 2002). Foi portanto o Prof. Dr. Luís Quintais o principal incentivador para a realização de um trabalho de campo num departamento de psiquiatria de um hospital distrital, com o objetivo de estudar as práticas, costumes, linguagens e significados dentro dessa comunidade.

A realização deste estudo de campo permitiu acompanhar, entre outros atores sociais, um interno de psiquiatria e observar a transformação deste em investigador, após ter sido convidado a apresentar uma comunicação oral num congresso de Psiquiatria Consiliar. Foi esta observação, aleatória, da multiplicação de práticas realizadas por um interno de psiquiatria, que permitiu registar e desvendar

17 Texto realizado com base na Tese de Mestrado "Despersonalização Voluntária do Ser" no âmbito do I Mestrado em Psiquiatria Cultural da Faculdade de Medicina da Universidade de Coimbra, orientada pelo Prof. Dr. Luís Quintais e coorientada pelo Prof. Dr. Manuel Quartilho. 
na comunidade estudada - departamento de psiquiatria de um hospital distrital - algumas das práticas associadas a uma outra comunidade, a comunidade científica.

Esta escolha de objeto de estudo teve várias consequências. Uma delas foi olhar para a ciência como uma forma de produção de conhecimento ocidental inserido num sistema cultural com algumas peculiaridades. Uma dessas peculiaridades é a sua descrição como sendo um objeto extracultural, ou pelo menos tentativa ilusória de o ser, visível nos artigos, livros e apresentações científicas. Uma explicação parcial, para a existência deste discurso dentro da ciência, é encontrada no pensamento de Karl Popper (Popper, 1999; Echeverria, 2003) que descreveu a ciência como a mais correta prática de produzir conhecimento, pois tinha como base uma metodologia que a tornava superior às outras formas de produção de conhecimento, a dúvida sistemática. Segundo este autor, a função do cientista não é descobrir a verdade, de forma direta, mas sim provar que uma teoria ou resultados são falsos e, desta forma, aproximar-se dessa mesma 'verdade'. Para isso acontecer o cientista deve manter-se neutro em todo o processo científico, prática que denominamos como Despersonalização da Ciência, pois despersonalização, segundo a terminologia psiquiátrica, descreve o que alguns indivíduos relatam como uma perceção ou sensação de desconhecimento/não reconhecimento de si mesmo, como se estivessem a sair do seu corpo (Trzepacz \& Baker, 2001). O cientista transmite essa ideia, de que é possível separar-se do seu ser cultural, homem inserido numa cultura, e produzir conhecimento e dados, isento de distorções culturais. Mas será que é isso que encontramos ao observar as suas práticas?

Apoiado pelas observações realizadas neste estudo e por outros semelhantes (Latour, 1987; Mol, 2002a e 2002b), consideramos que o cientista é parte integrante de uma comunidade, a comunidade científica, e que por isso será sempre condicionado por fatores sociais e culturais que nunca permitirão que o ator social cientista seja capaz de uma total neutralidade. Esta incapacidade, por parte do cientista, de não conseguir escapar às regras, preconceitos (modos predeterminados de observar o mundo, as relações e os objetos) e significados da sua própria comunidade, deve-se, entre outros, ao fato de ele também constituir um agente, com interesses pessoais, de preservação e reprodução das práticas e crenças da comunidade científica.

Ao considerar os cientistas como integrantes de uma comunidade, a(s) comunidade(s) científica(s), sugerimos um novo campo de estudo, a ciência como um produto social referente a comunidade(s), e devendo ser estudado como tal, pois os seus atores interagem entre si, interferem uns com os outros, moldam-se, unem-se ou afastam-se consoante diferentes situações, localizações, organizações e interações com outros sistemas culturais e outras comunidade(s) científica(s). Se assim é, estes fatores irão interferir na escolha dos objetos de estudo, isto é, irão influenciar e determinar o que pode ser estudado, o que é um objeto de estudo, quais os métodos que podem ser usados ou disponíveis, quais os mais credíveis, quais os fundos, meios humanos e técnicos disponíveis, etc. Por tudo isto, Larry Laudan (Echeverría, 2003) considerou que a comunidade científica nunca teve como finalidade diferenciar o 'verdadeiro' do 'falso', mas sim saber qual o número de problemas a que cada programa científico consegue responder. Segundo este critério, o cientista escolheria o seu programa científico 
e assim atribuiria sentido às suas práticas. Por outro lado, se é através de pareceres dados por estes programas científicos que muitas decisões políticas são atualmente realizadas, visto pretenderem responder a determinadas demandas sociais, a comunidade científica estará a reforçar a própria 'racionalidade teleológica'. Esta 'racionalidade' é a que privilegia as maiores forças de produção por detrás da sociedade moderna, a ciência e a tecnologia, pois considera que são estas as melhores ferramentas para solucionar os problemas (Habermas, 1968). Contudo, estes autores referem apenas teorias que enformam e determinam as práticas científicas, mas será que as práticas científicas não têm a sua própria agencialidade?

É a esta questão que o trabalho de Mol (2002a, 2002b) respondeu ao realizar uma praxiografia sobre a arteriosclerose. O seu trabalho de campo observou que a arteriosclerose multiplica-se segundo diferentes enactments, isto é, diferentes representações sociais transmitidas e mantidas através da ação de práticas e instrumentos sobre os objetos. Fornece como exemplo de diferentes enactments o caso do cirurgião vascular e do terapeuta da marcha perante um mesmo objeto, a arteriosclerose. Ambos lidam com a mesma doença, mas através de práticas diferentes, nem sempre concordantes, colocando a descoberto a complexidade da realidade médica em comparação com o que está descrito na literatura médica sobre o mesmo assunto.

Este estudo, mostra não só a agencialidade das práticas sobre os objetos - enactment -, como também exemplifica que a realidade não é capaz de ser englobada em formas simples de categorização, ordem ou análise (Mol, 2002a e 2002b; Law e Mol, 2002). Com esta afirmação não se pretende considerar a análise simplificada da realidade como o oposto da análise complexa da mesma, pretende-se sim uma análise da realidade mais honesta com a sua natureza, não totalmente passível de ser limitada, catalogada ou ordenada. Estes mesmos autores consideram que existem outras formas de analisar a realidade, ora através do desvendar da multiplicação do mesmo objeto quando sujeito a práticas diferentes - como mostrou Mol na sua etnografia sobre a arteriosclerose -, ora através de uma análise temporal não linear dos diferentes processos, ora através do recurso a listas, casos ou caminhos não determinados e não previstos. Realizar uma análise mais complexa da realidade implica acrescentar características aos objetos estudados, sem negar as simplificações anteriores, talvez acrescentando significado e permitindo o acrescentar de mais objetos, por não os excluir para as margens ou lugares de não existência.

\section{Visão parcial da realidade}

Para analisar comunidades, com a intenção de incorporar as suas perspetivas sobre a sua realidade social (incluindo as suas práticas), o método de estudo mais indicado é a observação participante, e as etnografias Science in Action de Bruno Latour (1987) e The Body Multiple: Ontology in Medical Practice de Annemarie Mol (2002a e 2002b) são exemplos deste tipo de estudos aplicados à ciência e práticas médicas. Ambos optaram por realizar trabalho de campo em locais poucos usuais: um laboratório de biofisiologia e um hospital, respectivamente. 
O presente estudo, a exemplo das etnografias citadas, constitui um trabalho de campo realizado num departamento de psiquiatria de um hospital distrital. A escolha desta comunidade hospitalar deveu-se ao fato de o etnógrafo já pertencer ao departamento que se propôs estudar, e por a psiquiatria ser uma área tanto do seu interesse como do interesse do seu orientador de tese de mestrado. Desta forma, o etnógrafo já estava integrado na comunidade estudada, o que levanta alguma questões relativamente ao método de estudo, nomeadamente as que dizem respeito à neutralidade das notas de campo obtidas através deste método. Citando Javier Echeverría:

Literalmente, a etnografia é um estilo de investigação em que o observador adota a atitude de um antropólogo que se encontra pela primeira vez perante certo fenómeno. Assumimos a perspetiva de um estrangeiro como meio de pôr em relevo as práticas comuns dos nativos que são objeto de estudo. Literalmente, etnografia significa 'descrição' do ponto de vista dos indígenas: em vez de impormos o quadro de referência próprio da situação, o etnógrafo tenta desenvolver uma apreciação da forma como os nativos veem as coisas. No caso da ciência, os nossos nativos são a comunidade de cientistas. Adotaremos as perspetiva segundo a qual as crenças, pressupostos e discurso da comunidade científica devem ser percebidos como algo de estranho. (Echeverría, 2003:279)

Este trecho explana bem o que é realizar uma etnografia, referindo que não é o objeto que tem de ser estranho ao etnógrafo, é a relação que este tem com o objeto que deve ser modificada de forma a que este seja percebido como algo estranho. Denominamos esta prática como despersonalização da ciência, (sendo despersonalização a perceção ou sensação de desconhecimento/não reconhecimento de si mesmo, como se estivesse a sair para fora do seu corpo). Foi esta técnica que permitiu estudar o objeto de estudo deste texto como algo estranho ao observador. Esta técnica, entre outras, é desvendada ao longo do texto como essencial para os processos de investigação na ciência. Caso não haja esta despersonalização ou neutralidade dos dados, estes podem ser rejeitados e anular qualquer interpretação que surja a partir deles.

Assim sendo, o recurso à observação participante, pelas suas características previamente descritas, permitiu uma observação dentro da própria comunidade mas exterior a ela, pois o etnógrafo modificou a forma como percebeu essa comunidade, que se tornou 'estranha' a ele. Foi este método que possibilitou a recolha de dados que sustentam este estudo. Não negamos que seja uma perspetiva parcial da realidade, mas como iremos mostrar, a ciência também o é, parcial, sem que esse fato tenha alguma vez impedido a sua produção conhecimento. Assumimos por isso as críticas de que a nossa opção metodológica produziu interferência (ou agencialidade) sobre todo o processo de elaboração, execução, recolha de dados e até no próprio processo de escrita deste mesmo texto. Não negamos estas interferências e, pelo contrário, aceitamos que estas interferências fazem parte deste estudo, bem como da própria ciência, pois são inerentes a qualquer outro processo de investigação, ainda que venham a ser escamoteadas por práticas e técnicas específicas da comunidade científica e as quais iremos desvendar. 


\section{O desvendar das práticas culturais por detrás de um discurso científico}

Como anteriormente descrito, este estudo tem como base as notas de campo criadas durante a observação participante, realizada entre janeiro e junho de 2008, num departamento de psiquiatria de um hospital distrital. Foi através destas notas que nos foi possível acompanhar e observar as práticas de um interno da especialidade de psiquiatria, incluindo a realização de um trabalho de investigação intitulado 'Perceções Externas à Psiquiatria'. Segundo Clifford Geertz (1978), as notas de campo são descrições densas da realidade que permitem, posteriormente, ao etnógrafo realizar uma interpretação contextualizada das suas práticas e significados.

Por questões de melhor exposição, optou-se por inicialmente transcrever, parcialmente, o discurso apresentado pelo interno da especialidade aquando da sua comunicação oral do trabalho de investigação 'Perceções Externas à Psiquiatria', para depois seguirmos um caminho não linear das suas práticas que nos possibilite desvendar os seus significados:

Em fevereiro de 2008, o diretor do meu serviço convidou-me a apresentar um trabalho para o Congresso de Psiquiatria Consiliar, a realizar-se na região do Departamento de Psiquiatria e Saúde Mental (DPSM). Aceitei esse desafio e propus falar sobre as perceções exteriores à psiquiatria. (apresentação oral do trabalho "Perceções Externas à Psiquiatria").

Percebe-se que o interno, no papel de investigador, agradece ao seu diretor de serviço e ao mesmo tempo transforma-o num agente espoletador do processo de investigação em causa. Adianta mais:

A escolha deste tema deveu-se à leitura de um artigo publicado em 1999, "Public conceptions of mental illness: labels, causes, dangerousness and social distance", de um autor americano, Bruce Link. (idem)

O interno refere o artigo de Bruce Link (1999) como um agente que forneceu a hipótese de estudo, 'conceções sobre a doença mental', e que iria a estudar:

No meu caso, não me debrucei sobre a população portuguesa em geral, nem mesmo da área de influência do Departamento de Psiquiatria e Saúde Mental mas sim, sobre as perceções que os médicos de família18 têm sobre a perturbação mental. (idem)

Declarando que escolheu estudar as crenças sobre a perturbação mental numa população especial, os médicos de família, porque:

18 Na apresentação original é referido "clínicos gerais", mas o mais correto é dizer médicos de família, razão pela qual foi mudado o termo neste texto. 
Creio que este é um assunto interessante e mais que indicado para um encontro de psiquiatria consiliar e de ligação. (idem)

Ao reler o discurso da comunicação oral 'Perceções Externas à Psiquiatria', encontramos uma narração linear, limpa, clara e com nexo causal muito bem definido: o convite pelo diretor de serviço é considerado o mote para o processo de investigação, ao passo que artigo de Bruce Link (1999) foi o elemento que forneceu a hipótese de estudo e os médicos de família são a população que interessou ser estudada. Mas, como será desvendado, este discurso não é mais do que a ponta do iceberg, ou seja, o visível, de um complexo processo de investigação, que ficou submerso e escamoteado pelo próprio discurso.

\section{IV.I Convite - Princípio}

Analisemos, uma vez mais, o discurso realizado pelo interno da especialidade aquando da sua comunicação oral, de forma a averiguar a informação fornecida como a causa espoletadora de todo o processo de investigação - o convite.

O convite, realizado de forma informal pelo diretor de serviço e dirigido ao interno da especialidade, durante a reunião semanal do departamento psiquiatria, modificou o comportamento deste, transformando-o em investigador, um papel adicionado pelo interno da especialidade (Goffman, 1959 e 1963). Podemos dizer que o convite é um 'atuante social' (Latour, 1987), visto incorporar agencialidade que irá modificar os comportamentos de outros atuante sociais, um deles o interno da especialidade. Uma dessas modificações foi transformá-lo em investigador. Mas quais são as práticas ou informações culturais que este atuante social - convite - transporta?

Uma delas foi encontrada nos 'Princípios e Normas Orientadoras dos Critérios de Avaliação dos Exames de Internato Médico', princípios estes que orientam quais os parâmetros que devem ser avaliado no final do internato de médico de psiquiatria:

\section{$(\ldots)$}

V - Trabalhos publicados/comunicados com interesse clínico para a área de psiquiatria (1,5 valores) VI - Atividades de Investigação relacionados com a área profissional (1 valor)

VII - Outros fatores de valorização profissional (Títulos, Sociedades Científicas) (0,5 valores)" (www.ordemdosmedicos.pt)

Estes princípios sustentam que a realização de trabalhos com caráter científico (comunicações, publicações e atividades de investigação) podem conferir 2,5 valores em 20 valores no exame curricular do exame final de especialidade. Este fato desvendado, mas não presente no discurso, está contido no convite, visto ir ao encontro do interesse do interno da especialidade, ao permitir a adição de uma comunicação e atividade de investigação ao seu curriculum vitae.

Mas as agencialidades incorporadas pelo convite não se esgotam aqui, pois ao percebemos que o interno está inserido num Departamento de Psiquiatria, coordenado por um Diretor de Serviço, este 
último não ficará indiferente às performances exteriores ao Departamento realizadas pelos seus internos e colaboradores. Assim sendo, o próprio convite, ao ser realizado pelo diretor de serviço, vai incorporar as intenções deste e do próprio departamento de psiquiatria. Uma delas é o desejo de reconhecimento pela comunidade psiquiátrica, obtido, segundo os costumes e crenças desta comunidade, através da produção de artigos e comunicações orais sobre investigações e abordagens clínicas desenvolvidas pelo próprio departamento. Segundo este encadeamento de intenções, o interno da especialidade posicionou-se como um instrumento ideal para realizar estes artigos e comunicações, uma vez que também ele tinha interesse em realizá-los. Esta foi uma relação simbiótica em que ambos saíram beneficiados. Por um lado o departamento de psiquiatria empenhou-se em mostrar uma imagem de excelência, que poderia atrair novos internos da especialidade e até psiquiatras, e por outro o interno da especialidade poderia enriquecer o seu curriculum, promover-se junto dos técnicos de saúde mental, e assim aumentar o seu círculo de contactos profissionais que lhe possibilitassem receber mais convites, realizar novas comunicações e melhorar, ainda mais, o seu curriculum. Esta foi a agencialidade trazida pelo atuante social convite sobre o interno da especialidade, explicando as modificações que causou sobre este último.

Mas revendo o discurso do interno, não encontramos praticamente nenhum destes atuantes sociais desvendados, existindo uma razão para isso, como irá ser demonstrado.

\section{IV.II Hipótese de estudo - Conflitos entre pares}

Como revelado anteriormente, o discurso do interno, durante a sua comunicação oral, descreve o artigo "Public conceptions of mental illness: labels, causes, dangerousness and social distance" de Bruce Link (1999) como a causa para a escolha da hipótese de estudo: 'conceções sobre a doença mental'. Esta noção de linearidade e causalidade do processo de investigação, não foi totalmente confirmada quando analisado o convite, pois, como foi mostrado, inúmeros atuantes sociais ficaram submersos (invisíveis) e que tiveram a sua agencialidade através do convite. Será que o mesmo se passou no caso da escolha da hipótese de estudo?

Uma das razões porque me interessei por este tema, é o fascínio que me tem provocado a interação entre colegas de especialidades diferentes, pois nem sempre ocorrem da forma mais cordial. Isto tem-me levado a questionar se falamos a mesma linguagem? Ou se temos as mesmas crenças sobre as perturbações mentais? (apresentação oral do trabalho "Perceções Externas à Psiquiatria")

Esta questão levantada pelo interno de psiquiatria na sua comunicação oral foi observada durante o trabalho de campo, sendo exemplo disso a seguinte transcrição:

Um médico de outra especialidade médica veio pedir ao interno de psiquiatria para observar, no serviço de urgência, um rapaz de 17 anos por este andar a fumar haxixe. Na verdade, após breve exploração por parte do interno de psiquiatria, ao falar com o outro médico, este revela que "o rapaz sentiu-se mal disposto e veio à urgência. Refere ter fumado um charro de haxixe antes." 
Após essa informação, o interno de psiquiatria indagou: "Mas qual é mesmo o problema do rapaz? Ele tem outros antecedentes, tal como consumir outras drogas?" Ao que o outro médico nada respondeu e por isso o interno propôs: "É uma situação urgente ou posso vê-lo com mais calma na consulta externa para a semana?".

A reação do outro médico não foi de agrado, proferindo a seguinte frase para o interno de psiquiatria: "Vejo que não quer trabalhar."

Por se ter apercebido dessa reação, o interno questionou o colega médico "Mas o que é que esperaria de um psiquiatria, de urgência, num caso de consumo agudo de haxixe?"

A que o outro médico lhe responde: "Se eu fosse psiquiatra saberia o que dizer num caso destes, para que ele deixe de fumar" (in Diário de Campo, 29 de fevereiro de 2008)

Para além destes problemas de comunicação entre o interno de psiquiatria (como acontece com outros psiquiatras) e médicos de outras especialidades, quando partilham os mesmos objetos clínicos - pacientes -, ao indagar o interno de psiquiatria, este informou que já tinha lido o artigo de Bruce Link antes do convite realizado pelo seu diretor de serviço. Acrescentou que o tinha lido aquando da realização de três trabalhos para o mestrado em Psiquiatria Cultural e que os tinha terminado há muito pouco tempo. Referiu que os trabalhos tinham sido sobre "Comunicação: O seu contributo para o processo terapêutico", "História da Psiquiatria: Movimento antipsiquiatria da década de 60-70 e suas repercussões" e "Estigma: Perspetivas históricas da doença mental e ligação com processos de estigmatização". Destes 3 trabalhos, após leitura, apenas o último referia o artigo de Bruce Link, apesar de tanto o trabalho sobre Estigma e sobre a História da Psiquiatria abordarem o tema das conceções sobre a doença mental. O desvendar deste interesse pessoal do interno, bem como da informação que estava a realizar um mestrado em psiquiatria cultural, tornou mais inteligível o surgimento de um artigo realizado por um médico de saúde pública - Bruce Link - sobre as conceções da população americana sobre as doenças mentais. Mais uma vez, a observação e questionamento das práticas do interno de psiquiatria desvendaram novos atuantes sociais, neste caso o mestrado em psiquiatria cultural e o trabalho sobre estigma e história da psiquiatria, ausentes da comunicação oral realizada pelo interno da especialidade.

\section{IV.III Metodologia - Caixas negras}

Numa primeira fase da comunicação oral do trabalho 'Perceções Externas à Psiquiatria' não se encontrou qualquer referência à metodologia que tinha sido usada, mas esta é uma prática comum no discurso científico. Há uma razão relativamente simples para este fato, a metodologia está, quase sempre, diretamente relacionada com a hipótese de estudo escolhida. Esta relação entre hipótese de estudo e metodologia, demonstra a agencialidade que alguns dos atuantes sociais recrutados pelo interno da especialidade, para a realização do trabalho 'Perceções Externas à Psiquiatria', exerceram sobre as práticas do interno da especialidade enquanto investigador. Encontramos esta agencialidade nesta transcrição: 
Usei o mesmo método de recolha de dados que no artigo de Bruce Link, um questionário que depois passei na população alvo. O questionário era fechado, com apenas 4 possibilidades de respostas: muito provável, provável, pouco provável e muito pouco provável. Para além disso, este questionário tinha como base 5 vinhetas clínicas, cada uma a representar um diagnóstico do DSM-IV: dependência de álcool; depressão major; esquizofrenia; dependência de drogas; e pessoa com problemas. (apresentação oral do trabalho "Perceções Externas à Psiquiatria")

Esta transcrição mostra que o interno optou por utilizar a mesma metodologia do autor do artigo que refere como fonte para a escolha da sua hipótese de estudo. O mesmo atuante social influenciou dois aspetos importantes do processo de investigação realizado pelo interno da especialidade. Esta escolha aparentemente linear e simples, que prevalece no discurso do interno da especialidade, não descreve realmente o processo pelo qual estas práticas foram escolhidas, nem as opções prévias que foram rejeitadas, como irá ser mostrado.

Antes do interno ter optado pelo questionário de Bruce Link, este tentou criar um novo questionário, com base no de Link, informação que não é encontrada em nenhuma parte da comunicação oral do interno. Esta informação só foi deslindável através da etnografia que acompanhou o processo de investigação do trabalho 'Perceções Externas à Psiquiatria', entretanto apagada ao longo do processo, e que permitiu presenciar os diálogos entre o orientador do interno e o interno da especialidade. Num desses diálogos, o orientador persuadiu o interno da especialidade a utilizar um questionário já validado para avaliar a hipótese de estudo escolhida. A observação deste diálogo, entre interno/investigador e o seu orientador, forneceu diversas informações que foram importantes para o desenvolvimento do processo de investigação. Uma primeira observação é que o orientador pode ser um atuante social importante para a escolha das práticas científicas, como foi o caso. A segunda é que o interno da especialidade estará limitado aos programas científicos já montados no seu departamento de psiquiatria (Echeverria, 2003), pois estes programas científicos irão influenciar a escolha das hipóteses de estudo e a metodologia a usar. Isto demonstrou que o contexto onde o interno da especialidade realiza o internato da especialidade é um atuante social, e que não é visível na comunicação oral por ele apresentada. A terceira e última constatação, é que os processos científicos recorrem a teorias, hipóteses estudo e metodologias (paradigmas) já aprovados ou utilizados por outros investigadores, como foi o recurso a um questionário. Uma das razões para o recurso a estes paradigmas é fato de eles funcionarem como caixas negras (Flusser, 1983; Latour, 1987). Este conceito de caixa negra não se aplica apenas ao questionário, mas também a todos os atuante sociais que exercem a sua agencialidade por serem caixas negras, isto é, objetos, instrumentos, experiências ou teorias já estabelecidamente aceites pela comunidade científica, ou na sua generalidade. Mais do que aceites, são questões fechadas que não necessitam de ser questionadas ou explicadas dentro da comunidade científica, podendo ser prontamente recrutados para o interior dos processos de investigação e assim acelerar a sua execução.

Desta forma, percebe-se que a escolha do questionário, por parte do interno da especialidade, não foi simples, nem linear, tendo sofrido agencialidade por diversos atuantes sociais, como o artigo 
de Bruce Link, orientador e recurso a caixas negras, que permitiram não só trazer credibilidade ao processo de investigação como acelerar a sua execução.

Muitas destas práticas vão ao encontro à ideia da 'ciência normal' de Thomas Kuhn (1962), em que a maioria dos cientistas procuram comprovar e reforçar um determinado paradigma reinante, fazendo-o através de instrumentos construídos com base nesse mesmo paradigma.

\section{IV.IV População a estudar - Persuasão}

No meu caso, não me debrucei sobre a população portuguesa em geral, nem mesmo da área de influência do hospital de Aveiro mas sim, sobre as perceções que os médicos de família têm sobre a perturbação mental. (apresentação oral do trabalho "Perceções Externas à Psiquiatria")

Na comunicação oral do trabalho 'Perceções Externas à Psiquiatria', o interno da especialidade define, mais uma vez, de forma clara a população que foi estudada - médicos de família, justificando a escolha desta população com recurso ao mesmo argumento que utilizou para a escolha da hipótese de estudo:

Uma das razões porque me interessei por este tema, é o fascínio que me tem provocado a interação entre colegas, mas de especialidades diferentes, nem sempre das formas mais cordiais. Isto tem-me levado a questionar se falamos a mesma linguagem? Ou se temos as mesmas crenças sobre as perturbações mentais? (apresentação oral do trabalho "Perceções Externas à Psiquiatria")

Surgem dúvidas relativamente ao motivo que levou o interno da especialidade a escolher especificamente os médicos de família entre tantas outras especialidades médicas. Uma dessas justificações foi encontrada na seguinte nota do diário de campo:

O interno que tenho seguido refere que quer aproveitar este trabalho ('perceções externas à psiquiatria') para aprofundar o relacionamento com os colegas de clínica geral, que são na sua opinião a primeira linha de combate das doenças (ou deveriam ser) e, posteriormente, realizar outro tipo de trabalho para melhorar os cuidados na saúde mental. Ele pretende começar com uma pesquisa dos seus modelos de atuação para depois saber o que se poderá fazer. (In Diário de Campo, 10/03/2008)

Assim, o interno pretendeu compreender os modelos explicativos das doenças mentais por parte dos clínicos gerais, porque considerou que eles são atuante sociais que têm agencialidade sobre o ato de referenciar pacientes para a psiquiatria, da mesma maneira que as crenças sobre a doença mental exercem agencialidade sobre a aceitação do diagnóstico psiquiátrico por parte do paciente.

Todos estes atuante sociais são revelados na comunicação oral do trabalho, ao contrário dos exemplos até agora analisados, o que nos fez interrogar sobre quais foram os critérios que levaram a que alguns atuante sociais fossem tornados visíveis e outros não. 
Ao realizar estas questões e recuando até à data do convite, encontramos um atuante social que esteve sempre visível - congresso de psiquiatria consiliar/ligação e psicossomática. Este atuante social trouxe sentido a tudo o que foi descrito até agora, pois, como veremos, teve uma agencialidade peculiar a partir do momento em que o interno aceitou o papel de investigador para o referido convite.

A psiquiatria consiliar/ligação (simplificamos o termo para tornar mais clara a nossa exposição) é uma subespecialidade psiquiátrica, que deriva da palavra em Latim Consilium, que significa conselho, consulta ou consultadoria, e que funciona como 'consultora' para outras especialidades médicas, aquando da suspeita de coexistência de patologia psiquiatria. Simplificando, o objeto clínico da psiquiatria consiliar são os pacientes orientados por outras especialidades clínicas. Na prática clínica, no hospital onde foi realizado o estudo de campo, há diferenciação entre pedidos de consulta e pedidos internos de colaboração. Os primeiros podem ser realizados por qualquer médico (hospitalar ou pertencente aos cuidados primários da área de referenciação desse hospital), ao passo que os pedidos internos de colaboração são exclusivos para pacientes que se encontrem internados no hospital. Apesar dessa diferenciação, mais espacial e temporal que clínica, a justificação para o pedido de colaboração tem sempre como base as conceções sobre as perturbações mentais que cada médico possuiu. Se assim é, qual terá sido a razão para a escolha dos médicos de família em detrimento das outras especialidades médicas?

Houve vários atuantes sociais para essa escolha, o primeiro observado foi a opinião dada por alguns médicos especialistas do departamento de psiquiatria, em conversas informais de 'corredor', em que alertaram o interno da especialidade para a possível sensação de ameaça que especialistas de outras áreas médicas poderiam ter ao ser-lhes proposto o preenchimento de um questionário sobre a sua conceção sobre a doença mental. Segundo aqueles psiquiatras, os outros médicos poderiam considerar que estavam a ser postos em causa os seus conhecimentos psiquiátricos ou a pertinência dos seus pedidos de colaboração. O segundo atuante social, recrutado pelo interno, foi o plano de reestruturação nacional dos serviços de saúde mental, que reduzia a área de intervenção do departamento de psiquiatria do interno e por último, dados epidemiológicos sobre a doença mental, que o informaram que a grande maioria das patologias psiquiátricas eram apenas acompanhadas pelos cuidados de saúde primários e só uma pequena parte, as doenças mentais mais graves, estariam ao cuidado de especialistas de saúde mental. Estes três atuantes sociais (opinião de colegas, plano de reestruturação e dados da saúde mental) recrutados em consonância com outros atuantes sociais como o congresso de psiquiatria consiliar/ligação, o artigo de Bruce Link, as conceções sobre a doença mental e o questionário, tornaram possível a construção de um argumento que se adaptasse à temática do congresso de psiquiatria consiliar:

... modelos explicativos das perturbações mentais (ou seja, identificar os modelos explicativos na população em geral, médicos de família e nos próprios psiquiatras e conhecer as suas diferenças) que possam contribuir para uma melhor compreensão do encaminhamento de doentes para as consultas e urgências de psiquiatria. (apresentação oral do trabalho "Perceções Externas à Psiquiatria") 
Este encadeamento de atuantes sociais permitiu integrar os interesse pessoais do interno da especialidade (psiquiatria cultural, curriculum, convite, etc), com os interesses do congresso (temática abordada) e com os interesses do departamento de psiquiatria do interno (representação e promoção). Para além disso, a aceitação da opinião dos colegas e a delimitação do estudo aos médicos de família da nova área de intervenção do departamento de psiquiatria, segundo o plano de reestruturação nacional dos serviços de saúde mental, possibilitou limitar a população a estudar apenas 159 médicos.

Estas práticas de construção de argumentos de persuasão são comuns na ciência (Latour, 1987), porque todos os investigadores necessitam de ser aceites por determinadas comunidades científicas, como o interno quis ser aceite pelos organizadores do congresso de psiquiatria consiliar/ligação, para manterem o financiamento ou apoio aos seus processos de investigação. Isto demonstrou que as comunidades científicas/congressos/sociedades são atuantes sociais sobre os processos de investigação desenvolvidos pelos investigadores, pois não só limitam as hipóteses de estudo, como quais critérios necessários para persuadir essa mesma comunidade científica/congresso/sociedade.

\section{IV.V Resultados - Encantamento}

A comunicação oral do interno, como é apanágio das ciências naturais, após expor a introdução, a hipótese de estudo, a metodologia e a população/objeto a estudar, apresentou os resultados da sua investigação:

Reconhecimento da doença. O que os resultados demonstram, é que os médicos de família consideram como perturbações mentais a depressão e a esquizofrenia. Nas outras vinhetas manifestaram mais dúvidas. Percebe-se isto quando pelo menos um terço destes médicos não consideram que seja uma perturbação mental. As pessoas com problemas não são consideradas como portadoras de qualquer patologia. (apresentação oral do trabalho "Perceções Externas à Psiquiatria")

Esta é uma transcrição sumária dos resultados, pois este não constitui o objetivo principal deste estudo, que se foca nas práticas utilizadas e a sua agencialidade sobre todo o processo de investigação. Neste ponto da comunicação o interno a especialidade finalizou a sua apresentação, com base nos resultados em cima referidos, com as seguintes conclusões:

(os médicos de família)

- Reconhecem como perturbações mentais: esquizofrenia e depressão major. (apresentação oral do trabalho "Perceções Externas à Psiquiatria")

Esta forma de narrar os resultados, simples e clara, esteve presente ao longo de todo o discurso do interno da especialidade e talvez com maior importância na conclusão da sua comunicação. Contudo, como tem sido observado, não coincidiu totalmente com as práticas que permitiram realizar o processo de investigação. 
Recuando para alguns slides prévios às conclusões finais apresentados pelo interno da especialidade, deparamo-nos com os seguintes gráficos:

\section{RESULTADOS}

\section{1) Reconhecer como Perturbação Mental}

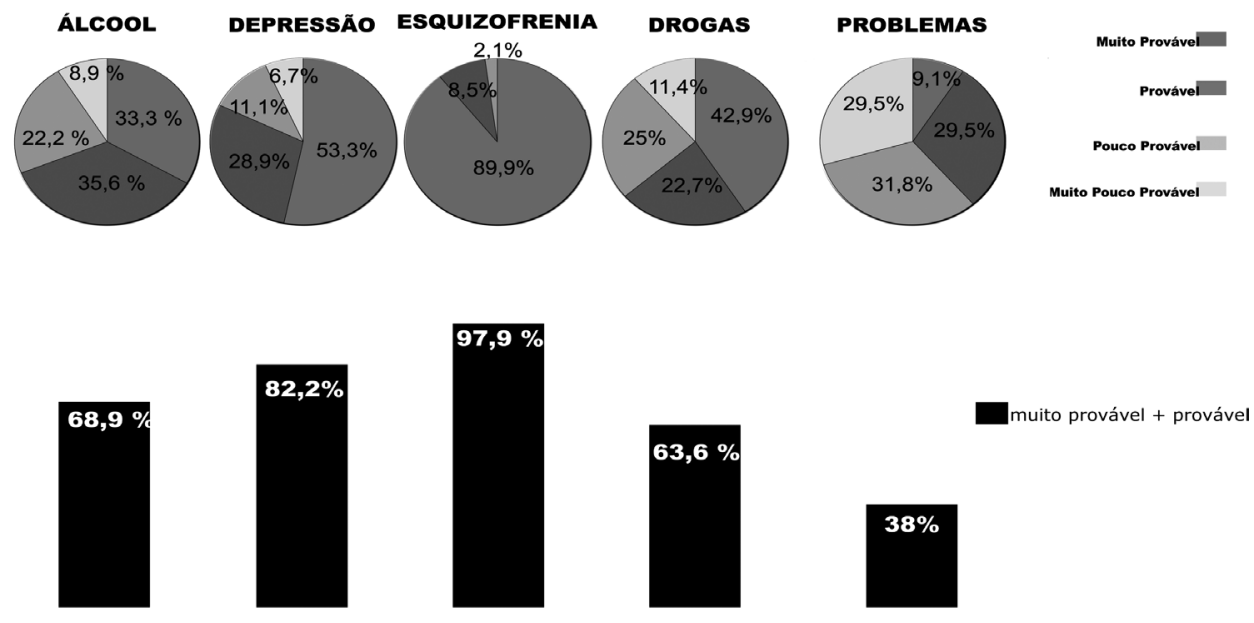

(Apresentação oral do trabalho "Perceções Externas à Psiquiatria")

Este slide mostra, para o caso da vinheta que representava Depressão, que apenas 53,3\% dos médicos de família responderam como sendo 'muito provável' constituir uma perturbação mental, 28,9\% como 'provável', 11,1\% como 'pouco provável' e 6,7\% como 'muito pouco provável', visto o questionário ser:

O questionário era fechado, com apenas 4 possibilidades de respostas, muito provável, provável, pouco provável e muito pouco provável. (apresentação oral do trabalho "Perceções Externas à Psiquiatria")

Mas há ainda a informação de que a soma das categorias 'muito provável' e 'provável', no caso da vinheta que representava a Depressão era de $82,2 \%$, o que o interno justificou:

Para facilitar a análise, como o próprio Bruce Link realizou no seu artigo, aceitei como resposta favorável a soma das respostas muito prováveis e prováveis (que corresponde à barra preta). (apresentação oral do trabalho "Perceções Externas à Psiquiatria")

E encontramos no artigo de Link (1999) essa confirmação: 
For ease of presentation, we dichotomized response categories, combining "very likely" and "somewhat likely" in one category and "somewhat unlikely" and "very unlikely" in another. In no instance did this dichotomization affect the direction or significance of an effect interpreted here. (in Link et al, 1999:1329)

Esta simplificação dos dados pretendeu facilitar a sua apresentação e baseou-se numa prática científica descrita por Latour (1993a) como a dicotomização, que, segundo este autor, comprova que a sociedade ocidental nunca foi moderna porque nunca conseguiu lidar com a realidade sem ser dessa forma.

Independentemente desta questão levantada por Latour, a simplificação é comprovadamente uma prática da ciência, a que o interno recorreu para conseguir com que a sua audiência, aquando da sua comunicação, fizesse uma leitura mais fácil dos seus resultados. Isto demonstrou duas coisas: o interno teve dificuldade em lidar com a complexidade inerente à realidade e intencionou orientar a audiência para uma determinada forma de interpretar os dados, tal como o fez Link no seu artigo (1999). Assim sendo, a simplificação dos dados obtidos pelo questionário para avaliar as 'conceções sobre a doença mental' teve como agencialidade a dicotomização da realidade e permitir persuadir a audiência para uma determinada interpretação dos dados. Mas será que referir que $82 \%$ de respostas são favoráveis, como o afirmou o interno, é o mesmo que dizer "Reconhecem como perturbações mentais: esquizofrenia e depressão major." ? Semanticamente não é, mas o interno teve a necessidade de traduzir os resultados em afirmações, pois de outra forma não iria encantar a sua audiência, como o disse o orientador do interno uns dias antes da sua comunicação oral:

À noite acompanhei o interno, visto este ter ido mostrar a sua comunicação ('perceções externas à psiquiatria') ao seu orientador. A razão, segundo ele, para o fazer deveu-se ao fato do orientador ser muito metódico, ter mais experiência em comunicações e mostrar gosto em ensinar e ajudar. Esta reunião, realizada num café, mostrou uma pessoa, o orientador, já com muitos anos de experiência clínica e na execução de comunicações, tendo fornecido muitas informações de como se devem apresentar os trabalhos e principalmente como devem ser dirigidas as discussões e conclusões finais. Uma das informações mais relevantes desse encontro foi de que na opinião do orientador, uma comunicação para ser interessante e eficaz, para além da metodologia de apresentação, que segue a regra: introdução, metodologia e população estudada, resultados, discussão e conclusões, deve conter, para além dos dados, alguma 'ousadia' e 'afirmações fortes', tal como uma possível interpretação dos resultados e não se ficar apenas pela simples exposição dos dados. (In Diário de Campo, 21/05/2008)

Esta agencialidade fornecida pelo orientador, mas que pode ser isolada e descrita como ousadia, encantamento segundo Gell, (1988, 1992), é a prática científica que torna dados subjetivos em afirmações, com base em crenças pessoais do investigador, não podendo ser dissociado dos programas científicos em que esteja inserido, pois este recorre a determinados paradigmas que irão enformar e dirigir a forma de olhar para determinados objetos e retirar conclusões (Kuhn, 1962; Echeverría, 2003). 
Este último atuante social, a ousadia, forneceu a última agencialidade que interferiu no processo de investigação desenvolvido pelo interno da especialidade e permitiu a construção de um argumento, com base nas próprias regras discursivas da ciência, mas em seu proveito, e fomentar o encanto da audiência, convencendo-a da sua validade, imparcialidade e afirmações finais sobre os resultados obtidos. Para isso, o interno recorreu aos atuante sociais recrutados ao longo de todo o processo de investigação, escolheu os mais fortes e adequados ao seu público - os que foram tornados visíveis na comunicação oral: convite, diretor de serviço, congresso de psiquiatria consiliar, artigo, questionário, dicotomização, etc.-, e encadeou-os de forma a construir um argumento adequado. O interno da especialidade culminou a sua argumentação com a exposição de resultados simplificados e de conclusões que não deixassem dúvidas à audiência. Se as deixou, essas dúvidas não foram consideradas como fracassos, mas sim transformadas em futuros estudos a realizar, pois como Kuhn (1962) postulou, trata-se de uma das práticas mais comuns da 'ciência normal':

Este é um estudo exploratório para futuros trabalhos relacionados com a descobertas dos modelos explicativos das perturbações mentais (conhecer os modelos explicativos na população em geral, médicos de família e nos próprios psiquiatras e perceber quais são as diferenças) que podem contribuir para perceber melhor o encaminhamento de doentes para as consultas e urgências de psiquiatria. Saber o que essas populações realmente pretendem da prática psiquiátrica. (apresentação oral do trabalho "Perceções Externas à Psiquiatria")

\section{Conclusão}

Este estudo desvendou os atuantes sociais visíveis, bem como os atuantes sociais escamoteados pelo discurso científico, associados a um processo de investigação intitulado "Perceções Externas à Psiquiatria", realizado por um interno da especialidade de psiquiatria.

Um desses atuantes sociais escamoteados ao longo de todo o processo foi a aceitação do papel de investigador por parte do interno da especialidade. Esta decisão, como mostrado, deveu-se à agencialidade de outros tantos atuantes sociais, uns visíveis, como o convite e o diretor de serviço, e outros invisíveis, como o curriculum e o exame de especialidade, que explicam a evolução das práticas utilizadas para a realização do processo de investigação e a sua agencialidade na escolha da hipótese de estudo, metodologia, população, resultados obtidos e conclusões.

O desvendar destes atuantes sociais, visíveis e escamoteados, demonstra que o processo de investigação estudado é, na verdade, um processo social inserido num sistema cultural, e que estes processos são transversais a toda a ciência (Latour, 1987; Echeverria, 2003; Hacking, 1992, 1995). Contudo, se fosse apresentado à comunidade científica e à comunidade leiga dessa forma, como uma sistema cultural repleto de interferências, perderia seguramente o seu poder de persuasão e de encantamento (Latour, 1987, 1993a; Gell, 1988, 1992). Uma das técnicas para ultrapassar esta limitação é construir narrativas científicas claras, lineares, com nexo de causalidade e imparciais. 
Este último ponto, a imparcialidade dos estudos, é essencial para a permanente diferenciação entre a ciência e outras formas de produção de conhecimento, e é conseguida através da despersonalização da ciência. Como demonstrado, esta é uma prática cultural específica da comunidade científica que the possibilita analisar a realidade de forma distanciada e neutra, permitindo posteriormente a construção de argumentos encantados. Conclui-se, portanto, que os atuantes sociais e as suas práticas devem ser desvendados e estudados como parte integrante dos processos de investigação e não devem ser escamoteados pelo discurso científico, pois esta é uma forma de simplificação da realidade, e o que se pretende são análises mais complexas, como foi intuito deste estudo, que se debruçou sobre as práticas científicas.

\section{Bibliografia}

Burns, T (2006). Psychiatry, a Very short introduction. OXford: OXford University Press.

Colégio de Psiquiatria. Princíplos e normas Orientadoras dos Critérios de Avaliação dos Exames de Internato Médico. Retrived FROM HTTP//WWW.ORDEMDOSMEDICOS.PT.

Comissão nacional para a Reestruturação dos Serviços de Saúde Mental. Reestruturação e Desenvolvimento dos Serviços de Saúde Mental em Portugal. Retrived from httP://Www. Portaldasaude.PT.

Csordas, T. (Mar., 1990). Embodiment as a Paradigm for Anthropology. Ethos, Vol. 18 (1), 5-47

Echeverría, J. (2003). Introdução à Metodologia da Ciência. Coimbra: Almedina.

Flusser, V. (1983), Ensaio Sobre a Fotografia: para uma filosofia da técnica. (nOVa Versão 1985). Lisboa: Relógio d'água. Foucault, Mi. (1976). The Birth of the Clinic An Archaeology of Medical Perception. (new version 2003) London: Tavistock Publications Limited.

Franklin, S. (1995). Science as Culture, Cultures of Science. Rev. Anthropolo Department of Sociology, vol 24, 163-184 Gell, A. (1988). Technology and Magic. Anthropology Today, Vol. 4 (2), 6-9.

Gell, A. (1992). The Technology of Enchantment and the Enchantment of Technology. In Coote, J \& Shelton, A. (eds), Anthropology, Art and Aesthetics. (pP. 40-66). Oxford: Clarendon.

Geertz, C. (1973). A Interpretação das Culturas. (nova versão: 1978). Rio de Janeiro; Zahar Editoras.

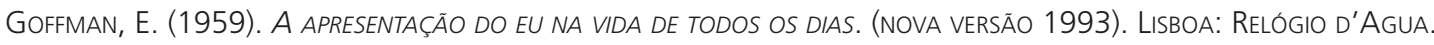

GofFMAN, E. (1963) ESTIGMA : NOTAS SObRE A MANIPULAÇÃo DA IDENTIDADE DETERIORADA. (NOVA VERSÃO: 1988). RIO de JANEIRO: ZAHAR.

Hacking, I. (1995). The Looping Effect of Human Kinds, In Sperber, D. \& Premark, A. (ed), Causal Cognition: An Interdisciplinary APPROACH (PP 351-383). OXFORD: OXFORD UNIVERSITY PRESS.

Hacking, I. (1998). Mad Travelers: Reflections on the Reality of Transient Mental Illnesses. Boston: Harvard University Press Habermas, J. (1968). TÉCNICA E CIênCIA COMO "IDEOLOGIA". Lisboa: EdIÇÕes 70.

KLEINMAN, A. (1980). PATIENTS AND HEALERS IN THE CONTEXT OF CULTURE (AN EXPLORATION OF THE BORDERLAND BETWEEN ANTHROPOLOGY, MEDIIINE AND PSYCHIATRY. BERKELEY: UNIVERSITY OF CALIFORNIA PRESS.

Kuhn, T. (1962). The Structure of Scientific Revolutions. (30 edition: 1996). Chicago: The university of Chicago Press.

Latour, B. (1987). SCIEnce in Action: How to Follow SCientists and Engineers Through SOCiety. Milton eynes: Open University Press. Latour, B. (1993). We Have Never Been Modern. Brighton: Harvester Wheatsheaf.

Latour, B. (1996), Joliot: a História e a física Misturadas, in Serres M. (ed). Elementos para uma História das ciências, vol. II, (PP. 131-155) .LISBOA: TERRAMAR. 
Link e tal. (1999). Public Conceptions of Mental Illness: Labels, Causes, Dangerousness and Social Distance. A M J Public HEALTH, VOL. 89, N 9, 1328-1333.

Link, B. \& Phelan, J.(2001) Conceptualizing Stigma. Annual ReView of Sociology, Vol. 27. (2001), pp. 363-385

Law, J., Mol, A. (2002). Complexities: Social Studies of Knowledge Practices. In J. Law \& A. Mol (Eds.), Complexities: An INTRODUCTION (PP. 1-22). DURHAM, DUKE UNIVERSITY PRESS.

Link, B. (1999). Public Conceptions of Mental illness: Labels, Causes, Dangerousness and Social Distance. A M J Public HEALTH, VOL. 89, No 9, 1328-1333

Link, B., Anglin, D. \& Phelan, J. (2006). Racial Differences in Stigmatizing Attitudes Toward People With Mental Illness. PSYCHIATRIC SERVICES, VOL. 57. 857-862.

Link, B., Pescosolido, B., Monahan, J., Stueve, A., \& Kikuzawa, S. (1999). The Public's View of the Competence, Dangerousness, and Need for legal Coercion of Persons With Mental Health Problems. Am J Public Health, vol.89, 1339-345.

Stueve, A. \& Link, B (1997). Violence and Psychiatric Disorders: Results from an Epidemiological Study of Young Adults in Israel. Psychiatric Quartely, Vol. 68 (No 4), 327-342.

Miller, D. (2001). Primitive Art And the Necessity of Primitivism to Art .In Susan Hiller (ed), The Myth of Primitivism: Perspetives on ART. (PP. 35-52). ROUTLEDGE

Mishima, Y. (1956). The Temple of the Golden PAVILION. London: Vintage International.

Mol, A. (2002A). The Body Multiple: Ontology in Medical Practice. Durham: Duke University.

Mol, A. (2002B). Complexities: Social Studies of Knowledge Practices. In J. LaW \& A. Mol (Eds.), Cutting Surgeons, Walking Patients: Some Complexities InVolved in Comparing (pp. 218-257). Durham, Duke University Press.

Murphy, D. (2001). Putting the biological and SOCIOLOGICAL tOGether IN EXPLANATION OF MENTAL ILLNESS. Philosophy of the SOCIAL SCIENCES, VOL. $31\left(N^{\circ} 2\right), 139-162$.

OKASHA, S. (2002), A VERY SHORT INTRODUCTION PHILISOPHY OF SCIENCE. OXFORD: OXFORD UnIVERSITY PRESS.

Popper, K (1999). A Vida É Aprendizagem: Epistemologia eVolutiva e sociedade aberta. Coimbra: EdiçÕes 70.

Porter, R (2002). MADNESS, A BRIEF HISTORY. OXford: OXford University PresS.

Quartilho, M. (2001). Cultura, Medicina e Psiquiatria. CoImbra: Quarteto Editora.

Quintals, L. (2000A). Liminaridade e Metamorfose: Uma Reflexão Antropológica sobre uma Desordem Psiquiátrica. Análise SOCIAL, VOL. XXXIV (153), 985-1005.

Quintais, L. (2000B). Memória e Trauma numa Unidade Psiquiátrica. Análise Social, vol. XXXIV (151-152), 673-684.

Quintals, L. (2001). Medicalizaçāo da Experienncia e Intencionalidade: A Aceitação de uma nosologia como Motivo e JUSTIFICAÇÃO DA HISTÓRIA. ETNOGRÁFICA, VOL 82, 325-334.

Quintals, L. (2002), O Teatro da Destruição e da Verdade e a Psiquiatria Portuguesa na Transição do Século xix. Separata da REVISTA DE HISTÓRIA DAS IDEIAS, VOL.23, 365-387.

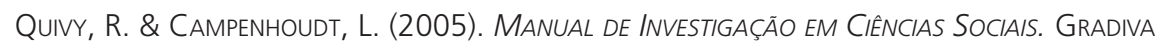

Rose, N. (2001). The neurochemical self and its anomalies. In Ericson (ed). Risk and Morality (pp. 407-437). Toronto: UnIVERSITY OF TORONTO PRESS, 2003.

Shorter, E (2000). Uma História da Psiquiatria, da era do Manicómio à IDAde do Prozac. (nOVa Versão 2001). Lisboa: CLIMEPSI EDITORES.

SAnjek, R. (ed) (1990), Fieldnotes: the makings of anthropology. New York: Cornell University Press.

Stoep, V. \& Link, B (1998). Social Class, Ethnicity, and Mental Illness: The Importance of Being More Than Earnest. Am J PuBliC HEALTH, VOL. 88, No9, 1396-1402. 